Article

\title{
Inorganic Waste Management in Greenhouse Agriculture in Almeria (SE Spain): Towards a Circular System in Intensive Horticultural Production
}

\author{
Samir Sayadi-Gmada ${ }^{1}$,*(D), Carmen Rocío Rodríguez-Pleguezuelo ${ }^{1}$, Fátima Rojas-Serrano ${ }^{1}$, \\ Carlos Parra-López ${ }^{1}$, Salvador Parra-Gómez ${ }^{2}$, Maria del Carmen García-García ${ }^{3}$, \\ Rosana García-Collado ${ }^{4}$, Mariana Beatriz Lorbach-Kelle ${ }^{5}$ and Trinidad Manrique-Gordillo ${ }^{4}$ \\ 1 Department of Economy of the Agri-food Chain, Institute of Agricultural Research and Training (IFAPA), \\ 18080 Granada, Spain \\ 2 Department of Agri-food Engineering and Technology, Institute of Agricultural Research and \\ Training (IFAPA), 04745 La Mojonera, Almería, Spain \\ 3 Department of Economy of the Agri-food Chain, Institute of Agricultural Research and Training (IFAPA), \\ 04745 La Mojonera, Almería, Spain \\ 4 Department of Prospective and Foresight, Andalusian Agency of Agriculture and fisheries \\ Development (AGAPA), 14004 Córdoba, Spain \\ 5 Department of Prospective and Foresight, Andalusian Agency of Agriculture and fisheries \\ Development (AGAPA), 04004 Almería, Spain \\ * Correspondence: samir.sayadi@juntadeandalucia.es
}

Received: 11 June 2019; Accepted: 5 July 2019; Published: 10 July 2019

check for updates

\begin{abstract}
The concept of circular economy, whose model is based on three main pillars: (i) design out waste and pollution; (ii) keep products and materials in use; and (iii) regenerate natural systems, has recently been applied to different sectors. This concept is directly related to bioeconomy. Spain implemented its own strategy in bioeconomy in 2016, affecting all economic activities, agriculture included. In line with this, one of the most important agricultural sectors is the greenhouse horticulture of Almería (SE Spain). This region has experienced deep changes in the last 40 years, and has become one of the most efficient agro-industrial complexes in the world. This rapid growth has brought sustainability problems such as pollution, water overuse, or inadequate waste management. Several studies have undertaken organic waste reuse or minimization, but an important lack of knowledge exists regarding the inorganic fraction. One of the goals of the REINWASTE project is to find solutions for this problem. Therefore, an extensive legal framework has been consulted and an in-depth study of the steps in greenhouse production with the associated residues has been carried out. Additionally, information from experts and stakeholders has been registered, resulting a list of Best Available Technologies (BATs) to prevent and minimize inorganic waste generation. This article highlights the intensive greenhouse horticulture from Almería efforts to reach circularity by closing the loop with inorganic waste.
\end{abstract}

Keywords: horticulture sector; greenhouse; REINWASTE project; inorganic waste; sustainability; circular economy

\section{Introduction}

\subsection{The Concept of Circular Economy in a Global Context}

By 2050, the main challenge for the global economy will be probably how to feed an increasing population by using fewer inputs and higher resource efficiency. In this sense, environmental problems, 
some of them of global scope, such as biodiversity, soil and water pollution, and overexploitation of resources are considerably endangering the worldwide ecological systems [1]. To overcome these environmental problems, as well as others of social or economic type, the concept of Circular Economy (CE) has gained importance [2]. More than 100 definitions have been proposed for this concept [3]. An economical system based on circularity pursues to redefine growth, focusing on positive society-wide benefits and to decouple economic activity from the consumption of non-renewable resources. According to Ellen MacArthur Foundation [4], the circular model is based on three main principles: (i) design out waste and pollution; (ii) keep products and materials in use; and (iii) regenerate natural systems. Additionally, this concept is directly related to that of Bioeconomy, which is, according to the definition given by the European Commission (2012) "the production of renewable biological resources and the conversion of these resources and waste streams into value added products, such as food, feed, bio-based products and bioenergy" [5]. Therefore, CE is a wider concept since it covers not only biological resources but it is effectively an economic system that replaces the "end-of-life" concept with restoration, promotes the use of renewable energy, eliminates the use of toxic chemicals and aims the elimination of waste by better design of materials, products, systems, and business models.

In general, when materials are extracted, they are utilized to produce services or products. These items are sold to consumers who later get rid of them (including waste and residues). Along the supply chain, waste and pollutants are derived, and some of them could be reused or recycled, but most of the time they get lost, mainly landfilled. It has been proven that this system exceeds the capacity of our planet to regenerate. As a consequence, a sustainable economic system must imperatively try to imitate the natural flows of the biosphere. In this sense, materials in the natural cycles move following circular flows of matter and energy, the concept of "waste" not being considered. Indeed, processes are "circular." Thus, circular economy replaces the concept of traditional linear supply chains by complex networks where materials are recycled and the word waste loses its common meaning to be considered potential food or product. According to the circular economy concept, any process may turn waste into higher value products or even transform them into inputs for other value chain production.

However, to perform this shift towards sustainable systems, several challenges are still needed: some of them are related to society and more especially to consumers. In a "linear economy," consumers are the last "step" of supply chains. In this situation, they are often completely passive and not concerned about their inherent condition of intermediaries between retailers and waste collection. Society as a whole must be familiar with the aims and principles of circular economy. In fact, there is currently an increasing concern about the impact of agriculture on the environment, waste generation, and visual landscape [6-8]. Thus, all stakeholders from the society must be involved in the implementation of a circular economy system.

\subsection{The Horticultural System in Almeria. The Problem of Inorganic Waste}

The area devoted to greenhouses in Europe is rising continuously. Spain and Netherlands are the countries with the largest greenhouse surface area. However, countries such as Italy, Greece, and France are expanding the area devoted to this type of farming

In this context, Almería is a province of southeast Spain $\left(36^{\circ} 50^{\prime} \mathrm{N} 02^{\circ} 23^{\prime} \mathrm{O}\right)$ characterized by a warm semiarid climate. The average temperature is $22^{\circ} \mathrm{C}$ and the rainfall is $225 \mathrm{~mm}$ (Figure 1). 


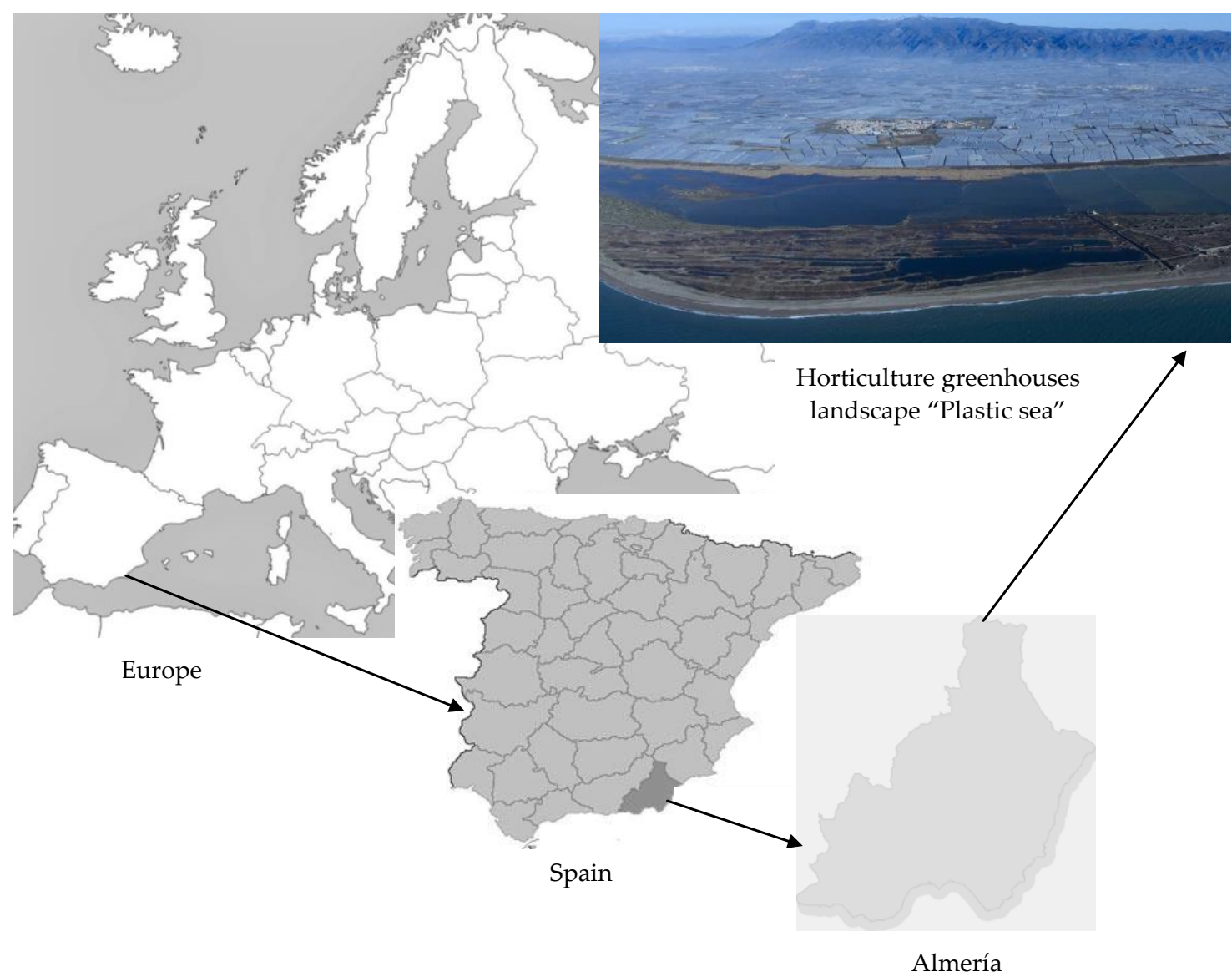

Figure 1. Location of the study area (Almería, SE Spain) and picture of the so-called "plastic sea."

The most important economic activity in this area is based on intensive horticultural cropping. Almería is currently a key worldwide reference from the point of view of inputs, resources use efficiency, and technical performance. Before the 60s, this region was considered one of the most depressed areas in Spain, the conditions for human life being unfavorable due to water scarcity, rough land, and frequent strong winds. However, after the 70s this situation drastically changed due to the implementation of intensive horticulture. In fact, from 1982 to 2003, this region was the major producer of horticultural products in Spain and Europe. Nowadays, it represents the highest extension of greenhouses, also commonly called the "plastic sea," due to the important visual landscape impact (Figure 1). Currently, there are over 35,000 ha under intensive horticulture production which produced 3,286,385 tons of horticultural products in the 2016-2017 campaign, with an average yield of $10.79 \mathrm{~kg} / \mathrm{m}^{2}$. The average surface of greenhouse farms ranges from 1.9 and $2.6 \mathrm{ha}$, with an average of five workers per farm. This high intensification has been described as the "Almería miracle" since it has been converted from the driest region in Europe into one of the most economically efficient areas in Spain [9,10]. This has been possible with the use of groundwater and more recently desalinized water, the high rate of sunny days and absence of thermal winters [11].

The main disadvantage of this rapid development was the absence of structured plans from institutions, and consequently the lack of concern of potential environmental problems [12]. In recent years, the specialization and number of devoted workers in greenhouses has increased with respect to the first employed people. It is also important to point out that the productive process employs more than 92,990 workers what results in an average of more than five workers per farm [13]. Most of the commercialization is based on cooperatives. At the beginning, products were placed in market by brokers acting as intermediates, which brought uncertainty to the commercialization of them [12]. 
In general terms, greenhouses in Almeria are characterized by a high efficiency protecting crops against climate and pests. The use of innovation and recent research results have allowed having several cropping cycles in a year. In this context of efficiency, Almería represents only $0.2 \%$ from the total agricultural area of Spain; however, it produces $20 \%$ of the total agricultural production and $60 \%$ of the horticultural production $[14,15]$.

As mentioned, greenhouse exploitations in Almería are in general small, being usually familiar structures, and considerably smaller than the average size of exploitations at a national and regional level (18 and 14 ha, respectively). In fact, the small size of exploitations is an added obstacle for adequate waste management.

Moreover, these greenhouses have the main disadvantage of being strongly dependent on external inputs. In this sense, efforts are being made to use smaller amounts of fertilizers. A new focus of farmers is introducing differentiation patterns in terms of quality. The knowledge of the end of life of the horticultural products as well as the associated waste destination is a differentiation attribute for the consumer.

Several studies and projects have been carried out to undertake studies for improving circularity in greenhouses (e.g., OrganicGH, EU Aquaponics Hub, Adapt2Change, etc.) but there is still an important lack of knowledge in the management of inorganic wastes, mainly plastics. Therefore, it is of imperative need to evaluate and overcome the characterization of the amount and type of inorganic waste at each step of horticultural production.

The basis of the circular economy is to make "someone's waste the resource of someone else" [16] and this is also in fact the main objective of the REINWASTE project. Thus, in this study, a characterization of the amounts and type of inorganic residues at each steps of greenhouse systems in Almeria, the existing legal framework, and potential practices (BATs-Best Available Technologies) for the sustainable management and reuse of inorganic waste are exposed.

\section{Materials and Methods}

In this study an extensive research of legislation was undertaken to clarify and establish the legal framework for inorganic waste management. Thus, all legal framework has been explored, not only that related to waste management, but also other legal aspects indirectly affecting residues in rural areas. European, national, and regional laws were tracked. Additionally, a state-of-the art study about intensive greenhouse horticulture in Almería was carried out. For this purpose, an extensive bibliography review, including national and international journals (databases such as Scopus or Dialnet were used), national and European statistics, recent local news, or official reports was performed.

Data for the estimation of generation of inorganic waste are made up from the knowledge of the production systems. This is supported by the existing information related to the use of materials, techniques and agronomic technologies and the level of implementation of them in field studies overcome by Valera et al. [17] and Castilla [18], by the characteristics of current used materials described by Serrano [19] as well as weight and volume [20] and its substitution according to life span of different elements and systems through the period of amortization and renovation [21].

Additionally, with the aim of finding available innovative solutions to reduce volumes of inorganic waste derived from the horticultural processes, a mixed methodology based on open information sources and an expert panel consultation was used. On the one hand, open information sources consulted range from EU projects or public outputs from R\&D institutes to service and innovative materials providers. Additionally, specialised websites in horticultural production, innovation, and circular economy were also checked. On the other hand, a panel of 27 experts was consulted mainly through face-to-face meetings, which were carried out in January 2019, with an approximate duration of $45 \mathrm{~min}$. The number of surveyed experts appears suitable as it is commonly accepted that in socio-economic research this figure should be over 17 , since the average error decreases for each consulted added expert $[22,23]$ and below 50 , since the predicted improvement is not appreciable from 
this quantity [24]. The utilization of a panel of experts has been recommended in those studies where there is a low rate of information about previous empirical evidences [25].

The involved experts had diverse profiles reaching different subjects, from intensive horticulture technology and innovation, to plastics and other materials for greenhouse horticulture, as well as waste management and recycling processes, as is shown in the list below:

- Technological centers devoted to plastics, innovation, and technology, the horticultural auxiliary and post-harvesting industry as well as horticultural greenhouse production technologies.

- Waste management organizations (plastics recycling and plant protection drums).

- Companies involved in the transformation of plastic materials (agricultural films) as well as suppliers of greenhouse structures and equipment or irrigation systems for intensive horticulture.

- Companies related to biological solutions for plant protection.

- $\quad$ Associations for plastic materials.

- Companies for materials recovery and fuels manufacturing.

- Horticultural producers' associations and agricultural consultants.

To overcome this consultation, a questionnaire was developed and sent previously by e-mail to the experts before face-to-face meeting, with a double objective:

- Identifying and quantifying the main inorganic waste sources in horticultural greenhouse production.

- Supporting the identification of the best available technologies, alternatives and solutions to reduce inorganic waste along the horticultural production process.

In this sense, the questionnaire included a table in which, for each identified type of waste (plastics for greenhouses, mulching plastics, strings, plant protection drums, chromotropic traps, clips, etc.), two types of data were collected: (i) information from the waste (type of materials, quantities, and level of contamination); and (ii) information about the alternatives to reduce this waste, organized by type (strategy, technology, new material, etc.), classification (prevention, eco-design, reusing, recycling, etc.) and technology knowledge levels.

Some experts provided alternative solutions which included not only answers to the questionnaire but also other technical information such as product datasheets and links or reports of interest. Other sources consulted provided information about the inorganic materials utilized for horticultural production as well as the amounts and characteristics of waste generated.

This information, together with the rest of the consulted sources, resulted in a complete description of the horticultural supply chain structure and subsequent generated waste, as well as an inventory table of best-advanced solutions for each type of source for the horticultural sector.

\section{Results and Discussion}

\subsection{Legal Framework for Circular Economy and Inorganic Residues Management}

The bioeconomy concept is related to the sustainable utilization of renewable resources for the production of food and feed, bio-based products, and bioenergy [26]. In this context, in 2012 the European bioeconomy had a turnover of almost 2 trillion $€$, creating more than 22 million positions. In the same year the European Union (EU) reaffirmed this trajectory by presenting the communication "Innovating for Sustainable Growth: A Bioeconomy for Europe" [27].

In this context, Spain implemented its own strategy on bioeconomy in January 2016. The implication of different economic sectors with the bioeconomy concept is estimated in $6.5 \%$ of the Gross Domestic Product (GDP) and employs approximately 9\% of the working population, within over 900,000 farms and more than 30,000 companies [28]. The relevance of food production in the Spanish economy is evident: the farming sector produced Gross Value Added (GVA) of 
21,707 billion $€$ of National GDP and employing 740,000 people [29]. GVA in the food industry sector was 28,500 billion $€$ in 2012 , with a total of 28,762 companies and employing 480,000 people [30].

Innovation, public, and private investment in bioeconomy are supported by European, national, and regional measures. At EU level, the applied frame policy is the Horizon 2020 as well as CAP (Common Agricultural Policy) for innovation in agro-food systems. Horizon 2020, the EU Framework Programme for Research and Innovation, considers three pillars, the so-called "Societal Challenges Pillar" among them, which encourages the promotion of research and innovation critical mass to get the adopted policy goals. In this Pillar, Societal Challenge 2 is related to "Food security, sustainable agriculture and forestry, marine and maritime and inland water research and the bioeconomy." This policy was linked to the CAP by the European Innovation Partnership (EIP) on Agricultural Productivity and Sustainability, which is a tool to promote innovation through several measures and supported by the second pillar of the CAP. In the same context, the Spanish National Plan for Research, Innovation and Development was established, in a parallel way to the Horizon 2020, having a similar structure. One of the main parts of this Plan is the so-called "challenges of Society." The second one is related to bioeconomy under the name "Food quality, safety and security; sustainable and productive agriculture; natural resource sustainability; marine and maritime, and inland water research." In this way, research entities and private companies can ask for financial support to carry out actions in this area. Additionally, the National Plan has included measure to promote innovation in territories and with different bioeconomy-related fields. Furthermore, all Autonomous Regions have adopted their own Research and Innovation Strategy for a Smart Specialization (RIS3) [31].

Additionally, taking into account that inorganic waste can have potential for the construction of a circular economy framework in intensive greenhouse horticulture, it is of imperative need to establish the legal bases and context of this type of forwarded economy.

On December 2015, the European Commission adopted an implementation package about the circular economy of direct application in enterprises and consumers, related with the fight against climatic change, and the protection and conservation of the environment. In the same context, the Commission held a conference in June 2015, by which a public consultation was established. In this process, advantages and benefits of a shift towards a circular economy for the EU were analyzed. The basic principles for this was "closing the loop" of the life-cycles of products through a higher reutilization and recycling, and generating economic and environmental benefits by maximizing the value and use of raw materials, products, and wastes, promoting energy saving and reducing greenhouse gases (GHG) emissions.

Furthermore, and directly related to the legal framework of this study, the EU considers five priority-areas for the expansion and promotion of a circular economy. In fact, these sectors, due to their special features and conditions (type of products, value chain specificity, environmental impact, dependence of certain materials in their production or extraction process, etc.), are more complex to satisfy the "circular" requisite. These are the following: plastics, food wastes, critical raw, wastes from building, and biomass bio-products, plastics being the most directly related to this paper. In January 2018 the European Commission published the "Strategy for plastics in a circular economy" which promotes the protection of the environment from pollution derived from plastics. In this line, the EU also intends to encourage expansion and innovation within this sector, thereby generating new investment opportunities and employment associated with the shift towards the circularity of this sector.

In Spanish context, the Ministry of Agriculture and Food (MAPAMA) started, in March 2017, several measures towards the strategy to follow within circular economy. It is a long-time frame which identifies five priority sectors: building industry, agro-food sector, industry, consumer goods, and tourism, with measures to be accomplished up to 2030. Some of the objectives, which may be related to this work, are (i) protecting the environment and guaranteeing public health by reducing the use of natural non-renewable resources by reusing wastes and sub-products in the production-cycle as secondary raw materials; (ii) promoting the life-cycle analysis study of products 
and implementing measures of eco-design, by reducing the use of hazardous substances in their fabrication, to prolong the wedge life; (iii) encouraging the effective application of the principle of waste hierarchy: waste generation prevention, reutilization, and recycling; (iv) promoting the innovation and global efficiency of production processes, by the adoption of measures such as the implementation of the environmental management systems; (v) encouraging innovative ways of sustainable consumption and sustainable services; (vi) making possible the transition from a linear economy to a circular economy, by facilitating transparency of processes and public awareness; (vii) fostering the use of common indicators, transparent, and accessible that allow understanding of the scale of implementation of circular economy.

Thus, circular economy is the general framework of this work since the final objective is the re-use and circularity of inorganic waste generated in intensive greenhouse horticulture in Almería. However, there are several legal sectors related directly or indirectly to inorganic waste management, and which are explained below. In this sense, Figure 2 presents a detailed exposition of the legal framework of waste management in rural areas.

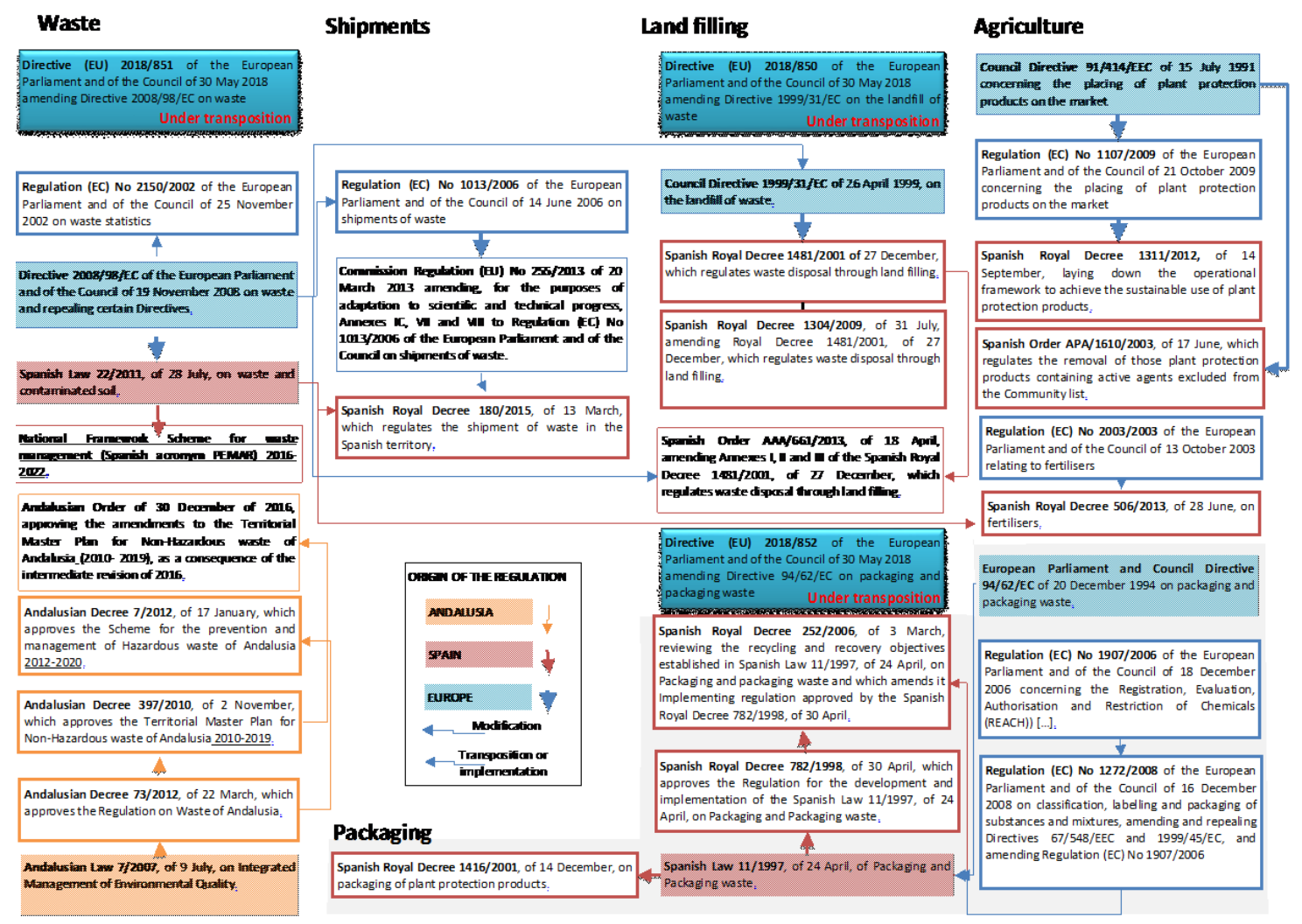

Figure 2. Legal framework for the management of inorganic waste in the primary sector. Source: own elaboration.

Legal framework for the management of inorganic waste in the primary sector can be classified in different areas:

1. Waste law context: the directive 2018/851 of the European Parliament on waste, which is currently under transposition. The Directive 2008/98/EC of the European Parliament on waste was transposed to the Spanish legal system by means of the Spanish Law 22/2011 on waste and contaminated soils, resulting in the National Framework Scheme for waste management (Spanish acronym PEMAR) 2016-2022) and posterior transposed to the regional Andalusian law system by the Order December 30, 2016 and other (see Figure 2).

2. Land filling: in many areas where recycling or incineration is not readily available, growers are faced with hauling the plastic to a landfill. The general European law frame is the Directive 
2018/850 on the landfill of waste which was transposed to the Spanish systems through the Spanish Royal Decree 1481/2001 which regulates waste disposal through land filling and the Spanish Royal Decree 1304/2009.

3. Packaging: in the European context, the current law of application is the Directive EU 2018/852 on packaging and packaging waste, which is under transposition. In Spain the legal frame is basically the Spanish Royal Decree 252/2006 (which reviews the recycling and recovery objectives established in Spanish Law 11/1997).

4. Agriculture: The Council Directive 91/414/EEC established the placing of plant protection products on the market. This law frame was developed by the Regulation (EC) No 1107/2009 of the European Parliament. The Spanish legal system assimilated these regulations by the Spanish Royal Decree 1311/2012.

In any case, society as a whole must be familiar with the aims and principles of circular economy and the sustainable management of residues. As a consequence, all stakeholders related to greenhouse horticultural production must be involved in the implementation of circular strategies towards "zero waste," circular economy being a tool to implement it [32]. This goal cannot be implemented unless this concept is well-perceived and promoted by society and all agents involved in horticulture greenhouse value chain.

\subsection{Analysis of the Different Processing Steps, Including Products and Main Activities in Intensive Greenhouse Horticulture}

For the development of agricultural production in greenhouses, it is necessary to overcome the following activities with their respective inputs and production factors:

1. Maintenance or renovation of agricultural infrastructures, including the following aspects:

a. Structure of greenhouses: wires, metallic tubes, plastics, and meshes used to avoid insects.

b. Irrigation systems: they can eventually be deteriorated due to chemical and/or biological blockage, as well as due to climate exposition (filtering equipment, valves, and irrigation emitters).

c. Replacement of covers: ageing due to exposure to solar radiation, chlorine, or sulphur.

d. Maintenance of ventilation systems: wires, metallic tubes, plastics, and meshes used to avoid insects.

Figure 3 shows the flows of inputs and waste in horticulture primary production. In this context, farmers buy all the inputs they need in specialised stores; in the case of large amounts needed, stores are responsible for transporting them to the warehouses located in the farms until they are applied. Once materials have accomplished their function, they are removed and separated for reuse and storage (they are applied up to the end of their lifespan). When these materials are not reused, they are collected until they are transported to the landfill or to the waste management company. These companies process residues and transform them into new raw materials that may be used in the auxiliary environmental industry, promoting plastic-recycling at the end of their lifespan, with different final purposes: packaging, agriculture, automotive, and building industries, etc. In other words, waste management companies generate new products which will definitely return to the productive system. 


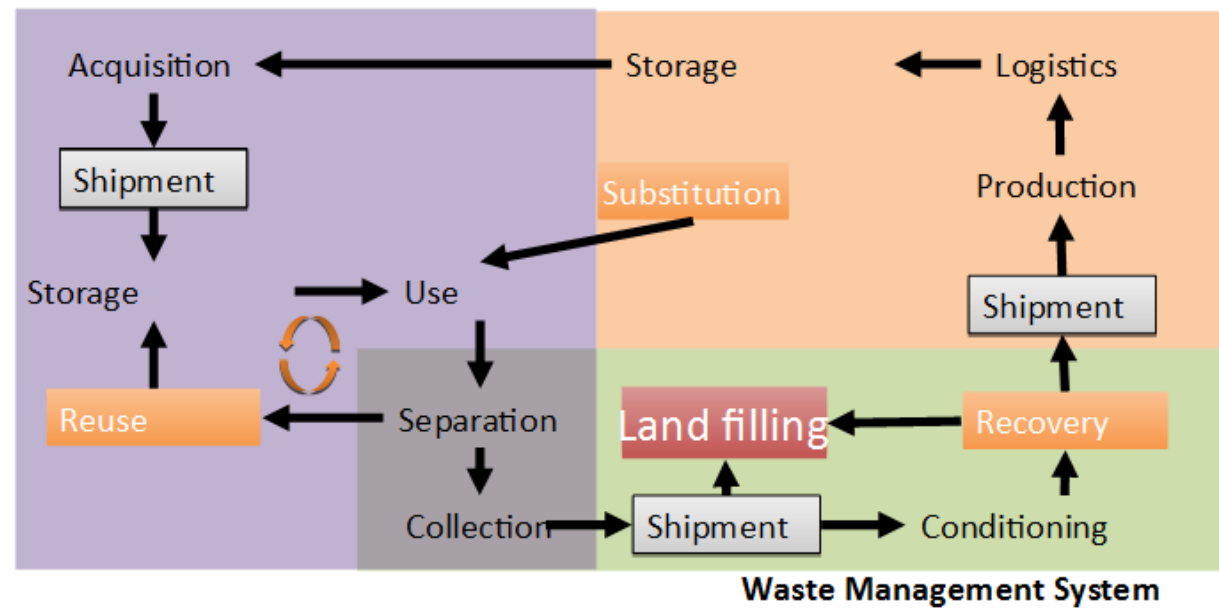

Figure 3. Flowchart of inputs and waste in the horticulture primary sector.

2. Preventive plant health measures: establishment of physical barriers in the soil (made up of plastic or agricultural fabrics), chromotropic plates, or pheromones. They are obtained in supplying stores. The plastic ones contain sand and remains of organic matter which both make the recycling difficult.

3. Sowing or transplanting: plants are directly sowed in the soil or in specialised nurseries and then taken to farms between 10 and 70 days after the sowing. Seedlings are transported in trays of seedbeds with plastic cases in cars (occasionally protected with a plastic film) when seedlings are transported by the nursery. This task is occasionally carried out by producers and broken trays are left in farms.

4. Biological control: auxiliary insects are transported to input warehouses or farms in plastic packaging kept inside refrigerated porexpan boxes.

5. Plant health treatments and fertilization: inputs are bought by suppliers and then stocked according to the current legislation to manage them compliant to the SIGFITO indications derived from regulations. The name SIGFITO comes from the Spanish name "Sistema de recogida de envases de fertilizantes y fotosanitarios," and it is a Spanish system used to collect the packaging of plant protection products. Some fertilizer supplying companies may not be included in the SIGFITO management system.

6. Pruning and defoliation: pruning and defoliation phases need to take especial prophylactic measures such as the use of gloves and cutting tools. They are obtained in specialized inputs stores.

7. Plant training systems: these systems use plastic and metallic by-products, such as raffia (string: supporting materials), clips, staples, hooks, and complex training systems. They are bought in inputs stores and, exceptionally, they are separated when crops are removed.

8. Harvesting: this process produces a great flow of plastic and wood material from the horticultural handling center. All the materials are controlled and returnable with the exception of the packing material and the raffia.

9. Fruit thinning: the same as for pruning and defoliation, this is, the use of gloves and cutting tools.

10. Crop removal: three different types of raffia can be found:

a. Biodegradable raffia: It is quite difficult to place them, but this task becomes easier after disposing some. Raffia is managed together with the crop once it has been removed as it is biodegradable. 
b. Reused plastic raffia: raffia, as well as hooks or plastic rings, can be reused for up to four years. The separation of the plants is carried out when controlling the plant training system and limiting the use of fastening elements [33].

c. Plastic raffia: this raffia goes together with crops to recycling plants. Raffia poses serious problems for composting plants as compost may decrease its qualification due to the presence of plastic materials.

11. Soil disinfection: it is necessary to distinguish between physical, chemical, biological, and mixed disinfections. By using biodisinfection, crop debris return to soil without transporting them. The plastics needed for solarization and chemical disinfectants are acquired in input stores. It is difficult to manage plastics as they usually contain dust and sand. Disinfectants packaging are included in the SIGFITO system.

\subsection{Data and Statistics on Amount, Volume, and Type of Produced Waste}

As mentioned before, the information relating to the production of inorganic waste in rural areas is atomized or almost non-existent. In general, with regard to the composition of this waste, the plastic used as protection material represents approximately $6 \%$ of the total waste produced in intensive horticulture and the remaining $94 \%$ correspond to organic residues.

The estimation for 35,000 ha dedicated to horticultural production in greenhouses shows that more than 90,738 tons of waste and a volume of $187,050 \mathrm{~m}^{3}$ are produced every year. The maintenance of the cover structure and the plastic for disinfection are the productive functions with a higher importance in respect to the weight ( $43 \%$ and $23 \%$, respectively). Regarding volume, the maintenance of the cover structure and transplanting are the most important contributing functions for inorganic waste $(27 \%$ and $22 \%$, respectively) of waste produced (Table 1 ).

Table 1. Annual distribution of waste according to their function in the farms of Almeria.

\begin{tabular}{ccccc}
\hline \multirow{2}{*}{ Function } & \multicolumn{2}{c}{ Weight } & \multicolumn{2}{c}{ Volume } \\
\cline { 2 - 5 } & $\mathbf{t}$ & $\mathbf{\%}$ & $\mathbf{m}^{\mathbf{3}}$ & $\mathbf{\%}$ \\
\hline Greenhouses & 39,215 & 43 & 49,798 & 27 \\
Substrates & 1219 & 1 & 1598 & 1 \\
Water storage & 576 & 1 & 730 & 0 \\
Disinfection & 21,061 & 23 & 24,066 & 13 \\
Shading & 10 & 0 & 10 & 0 \\
Transplanting & 698 & 1 & 40,714 & 22 \\
Tunnels & 2259 & 2 & 2429 & 1 \\
Padding & 4900 & 5 & 5065 & 3 \\
Supporting system & 6448 & 7 & 4891 & 3 \\
Irrigation & 4967 & 5 & 20,760 & 11 \\
Plant protection & 4034 & 4 & 17,333 & 9 \\
Pollination & 2469 & 3 & 26 & 0 \\
Harvesting & 2883 & 3 & 19,630 & 13 \\
Total & 90,738 & 100 & 187,050 & 100 \\
\hline \multicolumn{3}{c}{ Source: own elaboration. } \\
\hline
\end{tabular}

In addition, Table 2 shows the materials used to carry out the above mentioned tasks, and the main residues produced correspond to the metals of the greenhouses structures (41\%) and the low density polyethylene (LDPE) used in covers (38\%). 
Table 2. Estimation of the residual materials produced in 35,000 ha of intensive farming.

\begin{tabular}{ccccc}
\hline \multirow{2}{*}{ Material } & \multicolumn{2}{c}{ Weight } & \multicolumn{2}{c}{ Volume } \\
\cline { 2 - 5 } & $\mathbf{t}$ & $\mathbf{\%}$ & $\mathbf{m 3}$ & $\mathbf{\%}$ \\
\hline HD $^{1}$ polyethylene & 8669 & 10 & 36,599 & 20 \\
LD $^{2}$ Polyethylene & 34,034 & 38 & 55,249 & 30 \\
Metal & 36,921 & 41 & 27,968 & 15 \\
EVA $^{3}$ & 700 & 1 & 761 & 1 \\
Polypropylene & 4813 & 5 & 21,200 & 11 \\
Polystyrene & 191 & 0 & 40,159 & 21 \\
PVC & 140 & 0 & 112 & 0 \\
Mixed & 438 & 0 & 1872 & 1 \\
Mixed & 2917 & 3 & 428 & 0 \\
Wood & 284 & 0 & 231 & 0 \\
Latex & 58 & 0 & 647 & 0 \\
Concrete & 288 & 0 & 169 & 0 \\
Rockwool & 768 & 1 & 1097 & 1 \\
Coconut fiber & 452 & 0 & 502 & 0 \\
Sand & 67 & 0 & 56 & 0 \\
Total & 90,738 & 100 & 187,050 & 100 \\
\hline
\end{tabular}

${ }^{1}$ High density. ${ }^{2}$ Low density. ${ }^{3}$ Ethylene Vinyl Acetate. ${ }^{4}$ Plastics and other elements found in irrigation systems.

${ }^{5}$ Gloves used in harvesting. Source: own elaboration.

It is important to highlight that $5 \%$ of the weight produced correspond to polypropylene (raffia and supporting elements) which pose big difficulties in the management of organic waste.

Furthermore, the main types of inorganic waste produced in horticultural intensive production in Almería can be exposed by steps in the value chain. They are the following:

1. Materials used in the construction, maintenance and reform of greenhouses. These materials are mainly concrete and concrete prefabs, wires, plastic elements, agricultural fabrics, and elements of irrigation systems. The materials used in construction are managed by the builder. The replacement of cover and closing elements (plastic, wires, meshes) is carried out by professional staff. Plastic waste is collected separately from wires, cardboard, or mesh which are managed, not without difficulty by producers.

2. Materials for physical and chemical protection. Basically, they result from the elements used for the protection of the crop such as pads, tunnels, protections, double ceilings, and double closings together with the plastic used for solarization. This waste is produced when crops are replaced by others, especially in the summer period. Plastics are loaded onto vehicles for their shipment to the nearest management center or gathered in non-productive areas until they are transported to landfills.

3. Materials used in crop establishment. In this section transplant materials contained by plants produced in nurseries include:

- $\quad$ Trays, which are usually returnable.

- $\quad$ Covers, being usually disposable.

- $\quad$ Elements used to support plants (raffia, clips, and hooks).

- $\quad$ Packaging containing fertilizers (plastic or raffia sacks, cardboard boxes, plastic bags, and packaging that range from $25 \mathrm{gr}$ to $1000 \mathrm{~L}$ ).

- $\quad$ Plant protection products (paper sacks, plastic bags in cardboard boxes, plastic bottles that range from 0.25 to $25 \mathrm{~L}$ ) and auxiliary insects (cardboard boxes, cards, biofactory envelopes, cardboard, and plastic packaging that range from 0.25 to $1 \mathrm{~L}$ ).

In this context, seedlings and trays are managed by nurseries. Additionally, plant protection products, fertilizers and organisms for biological control and pollination are bought in input supplier 
companies. The packaging of plant protection products must be managed in SIGFITO, which is, as mentioned before, a system used in the Spain to collect packaging of plant protection products. To carry out this, containers are installed in different entities of the agricultural sector. Farmers can freely access these collection points and leave their empty packaging on a regular basis.

4. Materials used in harvesting. In this section, packaging of diverse standard sizes, pellet, straps, protection bags, and paper sheets are comprised. Farmers use the material provided by horticultural handling centers, fundamentally field boxes, which are provided under a use-return system.

5. Agricultural machinery. After the use of self-working machinery, oils, fats, filters, and batteries are produced when performing maintenance tasks. This waste is managed in the garages where they are repaired. Once their lifespan has finished, this waste is sent to an authorized management center (farmers can benefit from schemes for the renovation of machinery).

\subsection{Best Available Techniques (BATs) for the Management of Inorganic Residues of Greenhouses in Almería}

Based on experts' knowledge, we suggest a list of best-advanced solutions, technologies, or products available at EU level to reduce or avoid inorganic waste in horticultural production. These potential solutions are:

- Natural compostable string: this natural and compostable string is developed from recycled cotton yarns in addition to agronutrients. This product is set in the market, and has been tested before with pepper and tomato crops.

- Cellulose-rayon biodegradable string: this biodegradable string allows to carry out a new concept in the treatment of agricultural waste, permitting a cost reduction by not separating the string from the rest of organic elements once the crop has already finalized.

- Innovative reuse techniques for crop-supporting systems: Testing different material biodegradable strings for their reuse in horticultural greenhouse crops.

- Natural compostable chromotropic trap: made from natural fibers, dyes, and adhesives. Among the most important advantages of this product, is the total elimination of the residue of chromotropic traps that currently do not have an environmentally friendly channel for their disposal.

- Use of ultrasound emitter instead of insect sticky traps: employing an ultrasound emitter to avoid pests, replacing chemical plant protection products or insect sticky traps. The pilot tests were proven efficient against white flies, a very harmful pest for tomato, cucumber, or courgette crops.

- Innovation in auxiliary insects packaging used in biological pest control: packaging volume reduction and/or substitution by cardboard of auxiliary insect's plastic containers.

- Black biodegradable mulching plastic: made of biopolymer based on biodegradable and renewable raw materials and black smoke pigment to achieve an optimum level of opacity for application as agricultural mulch.

- $\quad$ Replacement of mulching plastic cover by straw layer: agricultural practice which consists of mixing soil with sand and cap with a straw mulching layer, avoiding the use of plastic cover.

- Strategic solutions for cleaning methods implementation of solarization and mulching plastics: testing of different washing, spreading, and drying methods for solarization and mulching plastics in greenhouses before their recycling in treatment plants.

- $\quad$ RAFU (Recycling of Used, Agricultural Films) machine: equipment to recover agricultural films with the purpose of recycling. It improves conditions for the collection and recovery of used farm film, significantly reducing the rate of pollution by using cleaning techniques closer to the place of use.

- Manual of best agricultural practices for sanded soil maintenance optimization: testing of best agricultural practices for a better maintenance of sanded soil in horticultural greenhouses. 
- White compostable clip: this compostable clip is also suitable for biological crops, combined with biodegradable string, and the cost of waste management can be reduced.

- Cleanable metal plant staking: promoting the use of metal plant staking instead of plastic plant staking, which can be cleaned and reused avoiding plastic waste.

- Inorganic waste management improvement in horticultural greenhouses: the monitoring of these types of waste in the horticultural greenhouses sector could favor the optimization of its sustainable management.

- $\quad$ Biodegradable strings of jute fibres: replacing plastic strings (raffia) used for staking plants with biodegradable strings. Different types of biodegradable strings using several raw materials (recycled cotton yarns and agro-nutrients, jute fiber, and other natural materials, cellulose-rayon) have been identified. These compostable materials allow avoiding separating strings from the rest of organic elements once the crop has been harvested, thereby permitting a cost reduction and the possibility of making compost on farms.

- $\quad$ Biodegradable mulching plastic films: biodegradable mulches provide an alternative to plastic mulch film for weed control, soil temperature moderation, water conservation, and other benefits. It avoids the collection and elimination of mulching at the end of the crop, thus allowing biodegradation and bio-assimilation in the field.

- Biodegradable and compostable clips. these clips are biodegradable and compostable and can be used to support various crops such as tomatoes, cucumbers, and peppers. The clips ensure enough support and a better orientation of the stem, not being necessary to wrap the stem of the plant along the wire, which reduces labor costs. The clips can be eliminated at the end of the crop cycle with the organic waste, not being necessary to separate them. They can be also sent for composting together with the crop, as it is not a contaminating element.

- $\quad$ Long lasting plastic cover. thermal film with EVA (Ethylene Vinyl Acetate)/EBA (Ethylene Butyl Acrylate), and metallocene polymers, manufactured in multilayer co-extrusion, in various thicknesses. It has one of the properties most valued by farmers-the impact on the dart (resistance of the sheets to a pressure exerted in a point) - therefore reinforcing a very important point in the covers-the folds. This sheet has been designed for greenhouses covers and crops tunnels, thus providing an excellent resistance to the degradation produced by solar radiation and chemical treatments.

- Second generation synthetic oil obtained from the recovery of a wide variety of waste, mainly plastic. Thus, alternative liquid fuels with commercial value result from pyrolysis, a thermal process where plastics are decomposed and transformed in lack of oxygen. There is already a commercialized product resulting from solid urban waste although the fuels obtained from agriculture plastics are currently in a testing phase. Nonetheless, they have been successfully used for greenhouse heating.

The last five Best Available Techniques (BATs) are the most outstanding ones. Furthermore, other potential solutions for horticulture farming to minimize and prevent inorganic waste could be natural compostable chromotropic traps (insect sticky traps). Innovations in auxiliary insect packaging used in biological pest control, replacement of mulching plastic covers by straw layers, or the implementation of other strategic solutions for cleaning methods of solarization and mulching, among others, complete the inventory.

\section{Conclusions}

Almería province, also popularly called "the larder of Europe" is characterized for having an intensive horticulture system based on greenhouses. Current efforts are being undertaken to obtain a more integrated and environmentally friendly model, by minimizing inorganic waste in the production process and therefore approaching the concept of circularity. 
Despite the fact that organic residues have more widely been characterized and studied for alternative purposes, the inorganic fraction management has not been efficiently undertaken. In this sense, the collaboration among all the stakeholders is imperative, i.e., academic sector, farmers, and agricultural institutions.

As it can be deduced from the best available techniques (BATs) presented in this work, there are great opportunities for improving the reduction of inorganic waste. A more efficient horticultural production which produces more with fewer resources and with less impact is possible. However, it is necessary to manage the waste generated in a proper way. Otherwise, it constitutes a risk to the economic, environmental, and social sustainability of the current productive model.

The achievement of circularity in this horticultural system is the way to enable coexistence of food security, economic expansion, and environmentally friendly solutions in support of "zero waste" generation. It is necessary to take into account that the basis of the circular economy is making somebody's waste, somebody else's resource. Subsequently, a sustainable management of inorganic waste can potentially develop a circular economy framework in intensive greenhouse horticulture.

Finally, REINWASTE contribution to a more circular horticulture in Almeria must be remarked, having different implications: (i) environmental (improvement of biodiversity, protection of soils, lower rate of pollution due to inadequate inorganic waste management, lower visual landscape impact); (ii) social (opportunities of higher quality and diversification of jobs, higher quality products based on environmental new labels such as "zero waste"); and (iii) economical (higher productive efficiency due to the application of new technological solutions, new value attributes for marketing strategies and product differentiation, willingness to pay for sustainable labels, satisfying different consumer niches and segment markets).

Author Contributions: S.S.G., Conceptualization, methodology, data collection, direction and review of the work; C.R.R.P., Writing-original draft; S.P.L. and C.G.G., Horticultural sector description; M.B.L.K., R.G.C. and T.M.G., Best Available Techniques (BATs) for the management of inorganic residues; F.R.S. and C.P.L., Editing of the paper.

Funding: This research was funded by REINWASTE PROJECT (3300) INTERREG NET PROGRAMME (ERDF).

Acknowledgments: We thank the European Commission for its support of the REINWASTE project implementation co-funded by the European Regional Development Fund.

Conflicts of Interest: The authors declare no conflict of interest.

\section{References}

1. World Wide Fund for Nature (WWF). Living Planet Report 2014: Species and Spaces, People and Places Gland. Available online: https://www.worldwildlife.org/pages/living-planet-report-2014 (accessed on 7 June 2019).

2. Brennan, G.; Tennant, M.; Blomsma, F. Chapter 10. Business and production solutions: Closing loops and the circular economy. In Sustainability: Key Issues, 1st ed.; Kopnina, H., Shoreman-Ouimet, E., Eds.; Routledge: London, UK, 2015; pp. 219-239.

3. Kirchherr, J.; Reike, D.; Hekkert, M. Conceptualizing the circular economy: An analysis of 114 definitions. Resour. Conserv. Recycl. 2017, 127, 221-232. [CrossRef]

4. Ellen McArthur Foundation. Towards the Circular Economy: Accelerating the Scale-up Across Global Supply Chains. Available online: http://reports.weforum.org/toward-the-circular-economy-accelerating-thescale-up-across-global-supply-chains/ (accessed on 7 June 2019).

5. European Commission. Innovating for Sustainable Growth. A Bioeconomy for Europe. Available online: https:/publications.europa.eu/en/publication-detail/-/publication/1f0d8515-8dc0-4435-ba539570e47dbd51 (accessed on 7 June 2019).

6. Salazar-Ordóñez, M.; Sayadi, S. Environmental care in agriculture: A social perspective. J. Agric. Environ. Ethics 2011, 24, 243-258. [CrossRef]

7. Sayadi, S.; González-Roa, M.C.; Calatrava-Requena, J. Public preferences for landscape features: The case of agricultural landscape in mountainous Mediterranean areas. Land Use Policy 2009, 26, 333-344. [CrossRef] 
8. Sayadi, S.; López-Moreno, F.J.; Calatrava-Requena, J. The landscape function of mango fruit orchards: Analysis of landscape social demand on the Spanish Costa del Sol. Acta Horticult. 2013, 992, 225-232. [CrossRef]

9. Mota, J.; Peñas, J.; Castro, H.; Cabello, J. Agricultural development vs. biodiversity conservation: The Mediterranean semiarid vegetation in El Ejido (Almería, Southeastern Spain). Biodivers. Conserv. 1996, 5, 1597-1617. [CrossRef]

10. Quintas-Soriano, C.; Castro, A.J.; Castro, H.; García Llorente, M. Impacts of land use change on ecosystem services and implications for human well-being in Spanish drylands. Land Use Policy 2016, 54, 534-548. [CrossRef]

11. Plan de Acción del Mediterráneo del Programa de Naciones Unidas Para el Medio Ambiente. 2009. Available online: https://wedocs.unep.org/rest/bitstreams/8030/retrieve (accessed on 7 June 2019).

12. Egea, F.J.; Torrente, R.G.; Aguilar, A. An efficient agro-industrial complex in Almería (Spain): Towards an integrated and sustainable bioeconomy model. N. Biotechnol. 2018, 40, 103-112. [CrossRef] [PubMed]

13. Análisis de la Campaña Hortofrutícola de Almería. Available online: http://www.publicacionescajamar.es/ pdf/series-tematicas/informes-coyuntura-analisis-de-campana/analiana-de-la-campana-hortofruticola-16. pdf (accessed on 10 June 2019).

14. Evolución de Macromagnitudes Agrarias en Almería. Anuario Estadísticas Agrarias y Pesqueras Andalucía 2016. Available online: https://www.analistaseconomicos.com/informe-anual-del-sector-agrarioen-andalucia-2016 (accessed on 7 June 2019).

15. Agriculture Ministry of Spain. Hortalizas: Serie Histórica de Superficie, Producción y Valor. Anuario de Estadística. 2017. Available online: https://www.mapa.gob.es/es/estadistica/temas/publicaciones/anuario-deestadistica/2018 (accessed on 7 June 2019).

16. Moreno, M.; de los Ríos, C.; Rowe, Z.; Charnley, F. A Conceptual Framework for Circular Design. Sustainability 2016, 8, 937. [CrossRef]

17. Valera, D.L.; Belmonte, L.J.; Molina, F.D.; López, A. Los Invernaderos de Almería. Análisis de su Tecnología y Rentabilidad, 1st ed.; Fundación Cajamar: Almería, Spain, 2014; p. 504.

18. Castilla, N. Invernaderos de Plástico. Tecnología y Manejo, 1st ed.; Mundi-Prensa: Madrid, Spain, 2004.

19. Serrano, Z. Guía Práctica del Empleo de Materiales Plásticos en Agricultura y Ganadería, 1st ed.; Zoilo Serrano: Madrid, Spain, 2011; p. 200.

20. Dupuis, I. Estimación de los Residuos Agrícolas Generados en la Isla de Tenerife, 1st ed.; Cabildo Insular de Tenerife: Tenerife, Spain, 2006; p. 20.

21. Cabello, A.; Barbero, J.; Martín, R.; Escobar, A. Contabilidad Agraria e Introducción a la Informática, 2nd ed.; Junta de Andalucía; Consejería de Agricultura y Pesca: Sevilla, Spain, 2004; p. 145.

22. Dalkey, N.C. The Delphi Method: An Experimental Study of Group Opinion, 1st ed.; Rand Corporation: Santa Monica, CA, USA, 1969.

23. García-Ruiz, M.E.; Lena-Acebo, F.J. Application of the Dephi Method in the Design of a Quantitative Investigation on the FABLABS. Revista de Metodologías de Ciencias Socials. Available online: https: //dialnet.unirioja.es/descarga/articulo/6411277.pdf (accessed on 10 June 2019).

24. Landeta, J. El Método Delphi. Una Técnica de Previsión Para la Incertidumbre, 1st ed.; Ariel: Barcelona, Spain, 1999.

25. Asselin, M.E.; Harper, M. Revisiting the Delphi technique: Implica tions for nursing professional development. J. Nurses Prof. Dev. 2014, 30, 11-15. [CrossRef] [PubMed]

26. McCormick, K.; Kautto, N. The Bioeconomy in Europe: An overview. Sustainability 2013, 5, $2589-2608$. [CrossRef]

27. European Commission (EC). Communication from the Commission to the European Parliament, the Council, the European Economic and Social Committee and the Committee of the Regions; European Commission: Brussels, Belgium, 2013.

28. Lainez, M.; González, J.M.; Aguilar, A.; Vela, C. Spanish strategy on bioeconomy: Towards a knowledge based sustainable innovation. N. Biotechnol. 2018, 40, 87-95. [CrossRef] [PubMed]

29. Main Economic Indicators for Agricultural and Food Industry. Ministry of Agriculture, Food and Environment. Available online: https://www.mapama.gob.es/AyPIndicadoresn12JUL2013_english_tcm3088444.pdf (accessed on 10 June 2019). 
30. Annual Report of the Spanish Food Industry Period 2014-2015, Ministry of Agriculture, Food and Environment. Available online: https:/www.mapa.gob.es/es/alimentacion/temas/industria-agroalimentaria/ Cifras-de-la-industria-alimentaria (accessed on 10 June 2019).

31. European Commission. Estrategias nacionales y Regionales Para la Especialización Inteligente (RIS3). Available online: https://ec.europa.eu/regional_policy/es/information/publications/brochures/2014/researchinnovation-strstrateg-for-smart-specialisation (accessed on 10 June 2019).

32. Wield, D. Bioeconomy and the global economy: Industrial policies and bio-innovation. Technol. Anal. Strateg. 2013, 25, 1209-1221. [CrossRef]

33. Torres, J.M. Uso Agronómico de Restos de Cosecha en los Invernaderos Enarenados de la Cuenca Mediterránea, 1st ed.; Fundación Cajamar: Almería, Spain, 2016; p. 84.

(C) 2019 by the authors. Licensee MDPI, Basel, Switzerland. This article is an open access article distributed under the terms and conditions of the Creative Commons Attribution (CC BY) license (http://creativecommons.org/licenses/by/4.0/). 